\title{
ESTADO DO CONHECIMENTO SOBRE ENSINO DE GENÉTICA EM PESQUISAS STRICTO SENSU
}

\author{
STATUS OF KNOWLEDGE ON TEACHING GENETICS IN STRICTO SENSUS \\ RESEARCH
}

Kely Cristina Gambin ${ }^{1}$, Neusa Maria John Scheid², Fabiane de Andrade Leite ${ }^{3}$

Recebido: dezembro/2020 Aprovado: junho/2021

\begin{abstract}
Resumo: Apresenta-se, neste artigo, uma pesquisa realizada com o objetivo de identificar trabalhos acadêmicos que tratam do ensino de genética na Educação Básica brasileira, tendo como foco o mapeamento de abordagens possíveis para o ensino e as estratégias de pesquisa utilizadas. O corpus da pesquisa se constituiu de dissertações e teses da Biblioteca Digital de Teses e Dissertações Brasileiras, nos anos de 1999 a 2019, utilizando o descritor "Ensino de Genética”. Por meio de análise qualitativa, identificou-se trinta e nove trabalhos publicados acerca da temática, sendo trinta dissertações e nove teses. Os resultados indicam que, nos trabalhos analisados, estudos acerca dos conceitos de Genética trabalhados na Educação Básica prevaleceram. Dentre esses conceitos, o DNA foi apontado como uma das principais dificuldades de aprendizagem dos alunos. Também foram empregadas diferentes estratégias de pesquisa, destacando-se a análise de recursos didáticos. Diante dos resultados, pode-se inferir que a expressiva publicação de temas relacionados ao ensino de Genética pode ser um bom indicativo de como as áreas de pesquisa em Educação e em Ensino tem priorizado essa temática. Isso pode indicar que há uma saudável preocupação com as questões referentes ao currículo, metodologia e concepções de ensino na área de Ciências da Natureza, com foco na Genética.
\end{abstract}

Palavras-chave: ensino de Biologia, livro didático, ensino de Ciências, ensino científico.

Abstract: This article presents a research carried out with the objective of identifying academic works that deal with the teaching of genetics in Brazilian Basic Education, focusing on mapping possible approaches to teaching and the research strategies used. The research corpus consisted of dissertations and theses from the Digital Library of Brazilian Theses and Dissertations, from 1999 to 2019, using the descriptor "Teaching of Genetics". Through qualitative analysis, thirty-nine published works on the theme were identified, with thirty dissertations and nine theses. The results indicate that, in the analyzed studies, studies about the concepts of Genetics worked in Basic Education prevailed. Among these concepts, DNA was identified as one of the main learning difficulties of students. Different research strategies were also employed, highlighting the analysis of didactic resources. In view of the results, it can be inferred that the expressive publication of themes related to the teaching of Genetics can be a good indication of how the areas of research in Education and in Teaching have prioritized this theme. This may indicate that there is a healthy concern with issues related to the curriculum, methodology and teaching concepts in the area of Natural Sciences, with a focus on Genetics.

Keywords: Biology teaching, didactic book, Science teaching, scientific teaching.

orcid.org/0000-0001-9746-1759 - Graduada em Ciências Biológicas. Pós-Graduada em Educação Ambiental. Mestranda do Programa de Pós-Graduação em Ensino de Ciências - PPGEC/UFFS Cerro Largo - RS. Professora da rede de Ensino Estadual de Dezesseis de Novembro - RS. Rua Santo Antônio, 1201, centro, CEP: 9784500, Dezesseis de Novembro. E-mail: kelygambin@hotmail.com.

2 iD orcid.org/0000-0003-1638-6019 - Doutora em Educação Científica e Tecnológica (UFSC). Pós-Doutorado em Educação Universidade de Lisboa. Pró-reitora de Pesquisa, Pesquisa e Pós-graduação da URI. Líder do GPECTS - Grupo de Pesquisa em Ensino de Ciências, Tecnologias e Saúde. Rua Estila Leal, 828, Bairro Pascotini, CEP: 98803190, Santo Ângelo. E-mail: scheid.neusa@gmail.com.

3 orcid.org/0000-0002-4967-233X - Doutora em Educação nas Ciências - Universidade do Noroeste do Estado do Rio Grande do Sul (UNIJUÍ). Professora Adjunta na Universidade Federal da Fronteira Sul (UFFS), Cerro Largo, Rio Grande do Sul, Brasil. Rua Jacob Reinaldo Haupenthal, 1.580, São Pedro, CEP 97900-000, Cerro Largo, Rio Grande do Sul, Brasil. E-mail: fabiane.leite@uffs.edu.br 


\section{Introdução}

O ensino de Genética na Educação Básica brasileira tem sido tema de discussões recorrentes em estudos que buscam qualificar os processos de ensino e de aprendizagem de Ciências, sendo o foco de investigação do presente artigo. Ao longo dos últimos anos, tais discussões se intensificaram, tendo em vista a implantação de um novo documento norteador do currículo no Brasil, a Base Nacional Comum Curricular (BNCC). O documento é organizado em áreas de ensino e, ao tratar da área das Ciências da Natureza, na unidade temática "Vida e Evolução", aborda a hereditariedade como objeto de conhecimento e habilidades a serem estudadas pelos anos finais do Ensino Fundamental, especificamente no 9o Ano. Ainda, no documento referente ao Ensino Médio, destaca-se que o ensino deve ser voltado a um debate mais ampliado acerca dos conhecimentos da área de Ciências da Natureza, tais como: DNA e suas tecnologias, células tronco, e suas formas de tratamento, entre outros (BRASIL, 2018).

Ressaltamos que a progressividade na abordagem dos conteúdos de Genética implica numa crescente complexidade dos temas abordados, o que acarreta a percepção, por parte dos alunos, de que os conteúdos são difíceis. Nesse sentido, Oca (2010) afirma que os conteúdos relacionados à Genética, geralmente, são classificados pelos alunos como difíceis e desinteressantes, uma vez que eles não conseguem fazer a associação de como é constituída a molécula de DNA, por exemplo, para a criação de um organismo transgênico.

Ademais, segundo Ferreira e Justi:

No âmbito das propostas dos PCNEM, o DNA é um tema que pode ser amplamente trabalhado mediante uma abordagem interdisciplinar, integrando principalmente as áreas de química e biologia, e promovendo uma relação entre as construções científicas $e$ tecnológicas que, por sua vez, pode imprimir mudanças de hábitos na sociedade. Para o ensino de biologia, os PCNEM deixam clara a necessidade da descrição do material genético em sua estrutura e composição, vinculada a uma abordagem que permita o desenvolvimento de um posicionamento criterioso relativo ao conjunto das construções $e$ intervenções humanas no mundo. (2004, p. 39).

Esse aumento de informações disponíveis, sem o entendimento dos conteúdos fundamentais, ainda ocorre atualmente, gerando a sensação de que são de difícil compreensão. Contudo, a importância dos conhecimentos de Genética a serem desenvolvidos em sala de aula, pode ser corroborada pela afirmação de Justina (2001, p. 91), de que "ela [a genética] representa, dentro da biologia, não apenas uma área de conhecimento, mas um caminho para mudar a natureza descritiva do ensino de biologia", pois é um tema integrador no estudo das Ciências Biológicas. De acordo com Scheid, no final do século XX,

o avanço do conhecimento na Genética se dá com uma rapidez espantosa, e os meios de comunicação o divulgam com eficiência ímpar, disponibilizando à população informações em discussão, mostrando que a ciência é um processo e não algo pronto. (2001, p. 82).

Desta forma, considerando o contexto atual de implantação de um documento norteador do currículo no Brasil, a Base Nacional Comum Curricular (BNCC), e a importância em manter estudos que tratam da temática do ensino de Genética na Educação Básica, foi realizada a 
presente pesquisa. Busca-se, assim, contribuir com reflexões acerca do ensino de Genética, com foco na melhoria da qualidade dos processos de ensinar e de aprender em sala de aula.

Assim, objetivou-se identificar trabalhos acadêmicos que tratam do ensino de Genética na Educação Básica brasileira, tendo como foco o mapeamento de abordagens possíveis para o ensino e as estratégias de pesquisa utilizadas. Com isso, pretende-se alcançar uma visão mais detalhada do ensino de Genética brasileiro, em especial no que refere ao Ensino Fundamental e Médio, nas disciplinas de Ciências ou Biologia.

\section{Procedimentos Metodológicos}

O processo metodológico da presente pesquisa é de natureza qualitativa, realizado a partir de uma revisão bibliográfica da literatura que, conforme Lüdke e André (2018), permite ao pesquisador um contato direto e prolongado com a situação que está sendo investigada, contribuindo de forma a alcançar resultados precisos, de modo que sirvam de referências teóricas e práticas para pesquisadores de determinada área.

Para tanto, fez-se um estudo bibliográfico em dissertações e teses que tratam da temática, buscando mapear o estado do conhecimento que, segundo Romanowski e Ens (2006, p. 39), "[...] aborda apenas um setor das publicações sobre o tema estudado". Para Morosini e Fernandes (2014, p. 155), "[...] estado de conhecimento é identificação, registro, categorização que levem à reflexão e síntese sobre a produção científica de uma determinada área, em um determinado espaço de tempo, congregando periódicos, teses, dissertações e livros sobre uma temática específica".

Entende-se que "nesta reflexão, faz-se necessário considerar que a construção de uma produção cientifica está relacionada não só à pessoa/pesquisador que a produz, mas a influências da instituição na qual está inserida, do país em que vive e de suas relações com a perspectiva global" (MOROSINI; FERNANDES, 2014, p. 156). Portanto, analisar o estado do conhecimento permite que se identifiquem pesquisas que vêm sendo desenvolvidas na área do ensino de Genética, capazes de contribuir para uma nova visão sobre a abordagem de seus conteúdos básicos.

Para a busca de dados, realizou-se um levantamento de estudos acadêmicos presentes na Biblioteca Digital Brasileira de Teses e Dissertação (BDTD), vinculado ao órgão nacional do Instituto Brasileiro de Informações em Ciência e Tecnologia (IBICT), considerando-se o período de 1999 a 2019. Esse período demonstra a evolução de pesquisas ao longo de vinte anos, proporcionando, assim, uma visão histórica do ensino dessa ciência, possibilitando que se entenda os caminhos percorridos, sem esquecer que podem ocorrer mudanças, se levarmos em consideração as políticas públicas.

No sentido de organizar os trabalhos separados para a análise, buscamos, por meio da leitura dos textos, as pesquisas acadêmicas relacionadas ao processo de ensinar Genética na Educação Básica, as estratégias de pesquisa realizadas e os conceitos trabalhados nos estudos. Com os dados organizados, realizamos a Análise Temática de Conteúdo, conforme proposta por Bardin (2011), seguindo as três etapas de análise: pré-análise, exploração do material, 
tratamentos dos resultados e interpretação. Na etapa da pré-análise, realizamos a busca e a leitura dos resumos das Teses e Dissertações, a fim de identificarmos aproximações com a temática proposta neste estudo. Para tanto, buscamos nos textos os conceitos acerca do ensino de Genética e, também, as estratégias de pesquisa utilizadas. Nesse processo, buscamos explorar o material, demarcando trechos para proporcionar uma melhor discussão e interpretação dos resultados.

\section{Mapeamento de Pesquisas acerca do ensino de Genética no Brasil}

Utilizando como descritor "Ensino de Genética", foram selecionados os trabalhos que apresentavam esse descritor como tema central de pesquisa, sendo encontrado um total de 39 trabalhos (30 dissertações e nove teses). Os resultados estão sumarizados no Quadro 1, a seguir. São utilizadas as indicações numéricas de P1 a P39, para as pesquisas, seguindo uma ordem de publicação, da mais antiga para a mais atual, com o título da publicação e o indicativo de T (teses) e D (dissertações), finalizando com a sigla da Instituição onde foi realizada a pesquisa.

Quadro 1 - Pesquisas acadêmicas que tratam do ensino de Genética no currículo brasileiro

\begin{tabular}{|c|c|c|c|c|}
\hline $\mathbf{P}$ & Ano & Título & $\begin{array}{c}\text { Tese/ } \\
\text { Dissertação }\end{array}$ & Instituição \\
\hline P1 & 1999 & $\begin{array}{l}\text { Aspectos da interação entre o professor de Biologia e } \\
\text { o livro didático no ensino de Genética, na cidade de } \\
\text { Pelotas, RS }\end{array}$ & D & UFSC \\
\hline P2 & 2001 & $\begin{array}{l}\text { Ensino de Genética e história de conceitos relativos à } \\
\text { hereditariedade }\end{array}$ & $\mathrm{D}$ & UFSC \\
\hline P3 & 2003 & $\begin{array}{l}\text { A Genética se faz presente no vestibular da } \\
\text { Universidade Federal de Santa Catarina }\end{array}$ & $\mathrm{D}$ & UFSC \\
\hline P4 & 2004 & $\begin{array}{l}\text { A produção coletiva do conhecimento científico: um } \\
\text { exemplo no ensino de Genética }\end{array}$ & $\mathrm{T}$ & UFSC \\
\hline P5 & 2005 & $\begin{array}{l}\text { Ensino de Genética: uma abordagem a partir dos } \\
\text { Estudos Sociais da Ciência e da Tecnologia (ESCT) }\end{array}$ & $\mathrm{D}$ & FURB \\
\hline P6 & 2005 & A resolução de problemas em Genética mendeliana & $\mathrm{D}$ & UFSC \\
\hline P7 & 2005 & $\begin{array}{l}\text { Avanços recentes em Biologia Celular e Molecular, } \\
\text { questões éticas implicadas e sua abordagem em } \\
\text { aulas de Biologia no Ensino Médio: um estudo de } \\
\text { caso }\end{array}$ & $\mathrm{D}$ & UNESP \\
\hline P8 & 2006 & A Genética humana no livro didático de Biologia & $\mathrm{D}$ & UFSC \\
\hline P9 & 2006 & $\begin{array}{l}\text { Conhecimento básico de Genética: concluintes do } \\
\text { ensino e graduandos de Ciências Biológicas }\end{array}$ & $\mathrm{D}$ & UNESP \\
\hline P10 & 2008 & $\begin{array}{l}\text { Diagnóstico das dificuldades de articulação e } \\
\text { sobreposição dos conceitos básicos da Genética } \\
\text { utilizando jogos didáticos }\end{array}$ & $\mathrm{D}$ & UFRPE \\
\hline P11 & 2009 & $\begin{array}{l}\text { O Jogo do Genoma: um estudo sobre o ensino de } \\
\text { Genética no Ensino Médio }\end{array}$ & $T$ & FIOCRUZ \\
\hline P12 & 2009 & $\begin{array}{l}\text { A argumentação na produção escrita de professores } \\
\text { de Ciências: implicações para o ensino de Genética }\end{array}$ & $D$ & USP \\
\hline
\end{tabular}




\begin{tabular}{|c|c|c|c|c|}
\hline P13 & 2010 & $\begin{array}{l}\text { A importância e o sentido de estudar Genética para } \\
\text { estudantes do terceiro ano do ensino médio em uma } \\
\text { escola da rede estadual de ensino em Gaspar (SC) }\end{array}$ & $\mathrm{D}$ & FURB \\
\hline P14 & 2011 & $\begin{array}{l}\text { Facilitando a Aprendizagem de Genética: uso de um } \\
\text { modelo didático e análise dos recursos presentes em } \\
\text { livros de Biologia }\end{array}$ & $\mathrm{D}$ & UFSM \\
\hline P15 & 2011 & $\begin{array}{l}\text { Ensino de temas da Genética Contemporânea: } \\
\text { análise das contribuições de um curso de formação } \\
\text { continuada }\end{array}$ & $\mathrm{T}$ & UNESP \\
\hline P16 & 2012 & $\begin{array}{l}\text { Conhecimentos básicos de Genética segundo } \\
\text { professores e docentes e sua apresentação em livros } \\
\text { didáticos e na academia: aproximações e } \\
\text { distanciamentos }\end{array}$ & $\mathrm{T}$ & USP \\
\hline P17 & 2013 & $\begin{array}{l}\text { Dificuldades de aprendizagem sobre conceitos de } \\
\text { Genética no Ensino Fundamental }\end{array}$ & $\mathrm{D}$ & UFRN \\
\hline P18 & 2014 & $\begin{array}{l}\text { Genética e suas aplicações: identificando o tema em } \\
\text { diferentes contextos de ensino }\end{array}$ & $\mathrm{T}$ & UFSM \\
\hline P19 & 2014 & O Ensino de Genética em Escolas Públicas de Goiânia & $\mathrm{T}$ & PUC-MG \\
\hline P20 & 2015 & $\begin{array}{l}\text { Heredogramas Familiares na Educação Básica: Ensino } \\
\text { e Aprendizagem pela Interdisciplinaridade e } \\
\text { Contextualização do Conhecimento. }\end{array}$ & $\mathrm{T}$ & UFSM \\
\hline P21 & 2015 & $\begin{array}{l}\text { A Genética no Ensino Fundamental: análise de um } \\
\text { processo de ensino a partir da perspectiva CTS } \\
\text { (Ciência, Tecnologia e Sociedade) }\end{array}$ & $\mathrm{D}$ & FURB \\
\hline P22 & 2015 & $\begin{array}{l}\text { Ambiente virtual de aprendizagem no ensino de } \\
\text { Genética }\end{array}$ & $\mathrm{D}$ & Univates \\
\hline P23 & 2016 & $\begin{array}{l}\text { Herança Multifatorial: Concepções de Estudantes de } \\
\text { Ensino Médio, Desenvolvimento e Aplicação de } \\
\text { Materiais Didáticos }\end{array}$ & $\mathrm{D}$ & UFSM \\
\hline P24 & 2016 & $\begin{array}{l}\text { Atividades Didáticas como Ferramentas Facilitadoras } \\
\text { na Compreensão de Imagens da Divisão Celular }\end{array}$ & $\mathrm{D}$ & UFSM \\
\hline P25 & 2016 & $\begin{array}{l}\text { O Ensino de Genética em Escolas Púbicas de Urucuia } \\
- \text { MG. }\end{array}$ & $\mathrm{D}$ & UFC \\
\hline P26 & 2016 & $\begin{array}{l}\text { O Portal do Professor como suporte para as } \\
\text { estratégias metodológicas no ensino de Genética }\end{array}$ & $\mathrm{D}$ & UFSC \\
\hline P27 & 2016 & $\begin{array}{l}\text { Discursos de Genética em livro didático: implicações } \\
\text { para o ensino de Biologia }\end{array}$ & $\mathrm{D}$ & UFRN \\
\hline P28 & 2017 & $\begin{array}{l}\text { Diálogos sobre Genética": uma análise sobre o } \\
\text { processo argumentativo em aulas de Biologia }\end{array}$ & $\mathrm{D}$ & UFRN \\
\hline P29 & 2017 & $\begin{array}{l}\text { Jogos digitais: uma vivência na sala de aula de } \\
\text { Biologia }\end{array}$ & $\mathrm{D}$ & UPE \\
\hline P30 & 2017 & $\begin{array}{l}\text { Desenvolvimento de uma sequência didática para o } \\
\text { ensino de Genética e seus aspectos químicos no } \\
\text { Ensino Médio }\end{array}$ & $\mathrm{D}$ & Unipampa \\
\hline P31 & 2017 & $\begin{array}{l}\text { Estratégias didáticas como proposta para o ensino da } \\
\text { Genética e de seus conteúdos estruturantes }\end{array}$ & $T$ & Fiocruz \\
\hline P32 & 2017 & $\begin{array}{l}\text { Objeto de aprendizagem digital como proposta de } \\
\text { ensino por Investigação em Biologia }\end{array}$ & $\mathrm{D}$ & UFMG \\
\hline
\end{tabular}




\begin{tabular}{|c|c|l|c|c|}
\hline P33 & 2017 & $\begin{array}{l}\text { Jardineiros intergalácticos: um jogo de tabuleiro para } \\
\text { o ensino de Biologia desenvolvido na perspectiva da } \\
\text { pesquisa baseada em design }\end{array}$ & D & UFSC \\
\hline P34 & 2018 & $\begin{array}{l}\text { O uso de textos de divulgação científica em aulas de } \\
\text { Genética na Educação Básica }\end{array}$ & D & UFSCAR \\
\hline P35 & 2018 & $\begin{array}{l}\text { Website estratégia genética: diretório de estratégias } \\
\text { Metodológicas para ensino de Genética }\end{array}$ & D & UFC \\
\hline P36 & 2019 & $\begin{array}{l}\text { Herança biológica e consanguinidade: Perspectivas } \\
\text { pedagógicas para o desenvolvimento do pensamento } \\
\text { científico }\end{array}$ & D & UPE \\
\hline P37 & 2019 & $\begin{array}{l}\text { O legado da educação básica para a alfabetização } \\
\text { Genética dos cidadãos }\end{array}$ & T & UFSM \\
\hline P38 & 2019 & $\begin{array}{l}\text { Ensino de Genética e Evolução para entendimento } \\
\text { da diversidade }\end{array}$ & D & UFMG \\
\hline P39 & 2019 & $\begin{array}{l}\text { Proposta de unidade de ensino potencialmente } \\
\text { significativa em Genética e Biotecnologia a partir da } \\
\text { análise do desempenho no Enem }\end{array}$ & D & UFJF \\
\hline
\end{tabular}

Fonte: Autores (2020).

No que se refere às abordagens possíveis para o ensino de Genética, propostas nos estudos, organizamos os trabalhos em três categorias, sendo elas: 1. Estudos que tratam de aspectos históricos do ensino de Genética; 2. Estudos acerca dos conceitos de Genética trabalhados na Educação Básica; e 3. Estudos de aspectos relacionados à Genética Moderna. Cabe destacar, que as categorias não são excludentes, ou seja, identificamos trabalhos em mais de uma categoria considerando a amplitude da discussão proposta. A organização dos trabalhos nas categorias de conteúdos de Genética está apresentada no Quadro 2.

Quadro 2 - Categorias acerca das abordagens do ensino de Genética apresentados nos estudos acadêmicos:

\begin{tabular}{|c|c|c|}
\hline Categorias & Trabalhos & Total \\
\hline $\begin{array}{l}\text { Estudos que tratam de } \\
\text { aspectos históricos do ensino } \\
\text { de Genética }\end{array}$ & $\begin{array}{l}\text { P1, P3, P4, P9, P26, P31, P32, } \\
\text { P33 }\end{array}$ & 8 \\
\hline $\begin{array}{l}\text { Estudos acerca dos conceitos } \\
\text { de Genética trabalhados na } \\
\text { Educação Básica }\end{array}$ & $\begin{array}{l}\text { P1, P2, P5, P6, P7, P8, P9, P10, } \\
\text { P11, P12, P13, P14, P16, P17, } \\
\text { P18, P19, P20, P21, P24, P25, } \\
\text { P28, P29, P30, P31, P32, P33, } \\
\text { P34, P35, P37 }\end{array}$ & 29 \\
\hline $\begin{array}{l}\text { Estudos de aspectos da } \\
\text { Genética Moderna }\end{array}$ & $\begin{array}{l}\text { P15, P22, P23, P26, P27, P28, } \\
\text { P36, P38, P39 }\end{array}$ & 9 \\
\hline
\end{tabular}

Fonte: Autores (2020).

Os estudos que focam em conceitos de genética, trabalhados na Educação Básica, foram identificados de forma mais recorrente nas teses e dissertações investigadas, tais aspectos foram encontrados em vinte e nove estudos. Ainda, observamos que os estudos que tratam de aspectos históricos e relacionados à Genética Moderna são realizados com menor frequência em estudos acadêmicos. 
A revisão bibliográfica realizada em dissertações e teses no Brasil, ao longo dos últimos 20 anos, permitiu-nos aferir informações relevantes acerca dos contextos de origem das pesquisas. Tais informações contribuíram para realizarmos uma caracterização dos estudos, identificando as regiões do Brasil em que foram realizados os trabalhos sobre o Ensino de Genética e, com isso, mapear a densidade das pesquisas na área no Brasil, conforme apresentado no Quadro 3.

Quadro 3 - Distribuição de Trabalhos de Pesquisa por Região do País

\begin{tabular}{|c|c|c|}
\hline Regiões & Número de trabalhos & Trabalhos \\
\hline Norte & 0 & - \\
\hline Centro-Oeste & 1 & $\mathrm{P} 25$ \\
\hline Nordeste & 7 & $\mathrm{P} 7, \mathrm{P} 9, \mathrm{P} 11, \mathrm{P} 12, \mathrm{P} 15, \mathrm{P} 16, \mathrm{P} 19, \mathrm{P} 31, \mathrm{P} 32, \mathrm{P} 34$, \\
Sudeste & 12 & $\begin{array}{c}\text { P1, P2, P3, P4, P5, P6, P8, P13, P14, P18, P20, } \\
\mathrm{P} 21, \mathrm{P} 22, \mathrm{P} 23, \mathrm{P} 24, \mathrm{P} 27, \mathrm{P} 30, \mathrm{P} 33, \mathrm{P} 37\end{array}$ \\
\hline Sul & 19 & \\
\hline
\end{tabular}

Fonte: Autores (2020).

A identificação das regiões brasileiras, das quais se originam os estudos, que tratam da temática de Genética no ensino de Ciências indicou a Região Sul como produtora do maior número de trabalhos, sendo dezenove dissertações e teses nessa região, o que corresponde a $48 \%$ do total das pesquisas realizadas com esse foco no Brasil. Na sequência, tem-se a região Sudeste com $30 \%$ dos estudos.

Outro aspecto relevante trata da periodicidade dos estudos, sendo que nos primeiros dez anos (1999-2009), foram encontradas doze pesquisas relacionadas à temática, e nos dez anos seguintes (2010-2019), o número de trabalhos que tratam do ensino de Genética aumentou consideravelmente, período em que houve a realização de 27 pesquisas acadêmicas. De acordo com Scheid e Ferrari (2006, p. 17), "muitas pesquisas têm sido realizadas com o objetivo de levantar e/ou analisar os conhecimentos e a compreensão que jovens estudantes têm sobre Genética, assim como a percepção sobre questões suscitadas pela aplicação das novas tecnologias genéticas em diversos contextos".

Corroborando o argumento das autoras, reiteramos a necessidade de permanecermos vigilantes acerca dos estudos que tratam do ensino de Genética no Brasil de forma permanente, pois, ao longo da última década, têm se intensificado discussões que tratam de alterações curriculares na Educação Básica brasileira, tais como para a aprovação da Base Nacional Comum Curricular.

Quanto às estratégias de pesquisa propostas nos estudos, identificamos oito objetos de análise diferentes utilizados pelos autores, sendo eles: livros didáticos, documentos, recursos didáticos, questionário, textos, diário de campo, argumentação falada e escrita e sequência didática. No que se refere ao uso de documentos como objetos de investigação nas pesquisas, 
os textos trazem análises de: provas de Vestibular, documentos oficiais (Constituição Federal de 1988, Lei de Diretrizes e Bases da Educação Nacional - LDB, Parâmetros Curriculares Nacionais - PCNs, Parâmetros Curriculares Nacionais para o Ensino Médio - PCNEMs e Base Nacional Comum Curricular - BNCC). Em relação aos questionários, observamos a utilização desse instrumento com professores e alunos da Educação Básica. Quanto à estratégia de análise de recursos didáticos, elencamos todos os trabalhos que apresentavam discussão acerca do uso de jogos didáticos em sala de aula, modelos didáticos e sequência didática.

A organização dos trabalhos nas estratégias de pesquisa identificadas está apresentada no Quadro 4.

Quadro 4 - Tipos de Estratégias de Pesquisas identificadas nos estudos acadêmicos analisados:

\begin{tabular}{|l|l|c|}
\hline \multicolumn{1}{|c|}{ Estratégias de pesquisa } & \multicolumn{1}{|c|}{ Trabalhos } & Total \\
\hline $\begin{array}{l}\text { Análise de diversos Recursos } \\
\text { Didáticos }\end{array}$ & $\begin{array}{l}\text { P6, P10, P11, P14, P15, P20, } \\
\text { P22, P23, P24, P25, P29, P31, } \\
\text { P32, P33, P35 }\end{array}$ & 15 \\
\hline $\begin{array}{l}\text { Realização de enquetes tipo } \\
\text { Questionário }\end{array}$ & $\begin{array}{l}\text { P9, P13, P16, P17, P18, P29, } \\
\text { P26, P37, P39 }\end{array}$ & 9 \\
\hline Análise de Livros Didáticos & P1, P4, P7, P8, P27 & 5 \\
\hline Análise de Sequência & P30, P36, P38 & 3 \\
\hline Didática & & 2 \\
\hline Análise de Textos & P12, P34 & 1 \\
\hline Análise de Documentos & P3 & 1 \\
\hline Análise de Diário de Campo & P21 & 1 \\
\hline $\begin{array}{l}\text { Utilização de argumentação } \\
\text { falada e escrita }\end{array}$ & P28 & \\
\hline
\end{tabular}

Fonte: Autores (2020).

Está presente como estratégia de pesquisa, a análise de diversos livros didáticos, já que esteve presente em cinco estudos (quatro referentes ao Ensino Médio e um ao Ensino Superior).

Sobre a importância do desenvolvimento de estudos relativos ao livro didático, Güllich destaca:

Pesquisas com bases empíricas na área de educação em Ciências tem apontado que os professores utilizam o livro didático quase em caráter exclusivo e em geral ainda não possuem formação adequada para (re) pensar e refletir sobre seu papel na Escola, bem como sobre novos e possíveis encaminhamentos para tal". Entendemos que o processo de ensino é o resultado de diferentes didáticas, e uma delas tem o livro didático (LD) como principal ferramenta, em virtude de sua grande distribuição e aceitação. (2013, p. 26) 
Logo em seguida à análise dos livros didáticos, foram identificados três estudos que tiveram sua atenção voltada para a sequência didática, estratégia que, conforme Zabala (1998, p. 54), tem como objetivo:

[...] introduzir nas diferentes formas de intervenção aquelas atividades que possibilitem uma melhora de nossa atuação nas aulas, como resultado de um conhecimento mais profundo das variáveis que intervêm do papel que cada uma delas tem no processo de aprendizagem dos meninos e meninas.

Em um excerto do trabalho P30 (2017), encontramos o relato de que o objetivo de "[...] desenvolver uma sequência didática foi integralmente alcançado, visto que foram elaborados diversos materiais". Igualmente, são destacados os resultados sobre o ganho na aprendizagem com um percentual bastante significativo: “[...] que vem ao encontro dos avanços tecnológicos apresentados nos dias atuais, que fazem parte do cotidiano do aluno, poderemos notar que é uma importante metodologia". Consoante a isso, pode-se compreender que a sequência didática pode auxiliar na compreensão dos aspectos envolvidos nos conteúdos de Genética, tornando-a menos difícil para aqueles estudantes que apresentavam dificuldades.

Verifica-se que a estratégia referente à análise de demais recursos didáticos aparece com a maior frequência, tendo sido identificada em quinze das pesquisas analisadas. Pode-se compreender que a preocupação com questões metodológicas ocupa um papel preponderante entre os pesquisadores brasileiros, em nível de stricto sensu, nos últimos vinte anos. Essa preocupação surge como importante, pois de acordo com Bandeira (2009), "o material didático pode ser definido amplamente como produtos pedagógicos utilizados na educação e, especificamente, como o material instrucional que se elabora com finalidade didática" (BANDEIRA, 2009, p. 456).

Em relação a essa constatação sobre recursos didáticos, Della Justina e Ferla (2006, p. 39) ponderam que o "ponto positivo é a facilitação da compreensão e da aprendizagem do processo biológico em questão e os pontos limitantes estão associados à forma de aplicação do modelo didático". Em vista disso, Scheid e Ferrari (2006) ressaltam a importância de que o professor tenha uma adequada concepção de natureza da Ciência para que, então, possa selecionar os recursos didáticos que facilitarão a abordagem do conteúdo, com uma postura epistemológica, favorecendo o protagonismo do estudante, e, além disso, torne-o emancipado em relação ao processo de aprendizagem.

Nesse sentido, os recursos, tais como os jogos didáticos, podem contribuir, conforme encontra-se expresso nas Orientações Curriculares para o Ensino Médio:

o jogo oferece o estímulo e o ambiente propícios que favorecem o desenvolvimento espontâneo e criativo dos alunos e permite ao professor ampliar seu conhecimento de técnicas ativas de ensino, desenvolver capacidades pessoais e profissionais para estimular nos alunos a capacidade de comunicação e expressão, mostrando-Ihes uma nova maneira, lúdica, prazerosa e participativa de relacionar-se com o conteúdo escolar, levando a uma maior apropriação dos conhecimentos envolvidos (BRASIL, 2006, p. 28). 
Outra estratégia identificada, nas pesquisas analisadas, foram as enquetes do tipo questionário, utilizadas para realizar levantamento dos conhecimentos prévios ou já adquiridos pelos estudantes sobre os temas abordados. Para ilustrar, pode-se destacar a pesquisa P9 (2006, p. 8), que afirma: “[...] através de uma pesquisa qualitativa, com o auxílio de questionários, verificar qual o conhecimento mínimo de genética básica dos concluintes do ensino médio, e também dos graduandos de ciências [...]".

Verificamos também a frequência, embora em menor quantidade, de outras estratégias de pesquisa que foram utilizadas para avaliar a aprendizagem relacionada à Genética: análise de textos, documentos, diários de campo, argumentação falada e escrita. Dessa forma, pode-se vislumbrar a diversidade de estratégias utilizadas para buscar respostas a questões cruciais no processo de ensinar e de aprender Genética. Na próxima seção, trataremos das abordagens do ensino de Genética, propostas nas publicações analisadas, referentes a um período recente de vinte anos de pesquisas em programas de pós-graduação stricto sensu em nosso país.

\section{Abordagens para o ensino de Genética propostas em Teses e Dissertações}

A leitura dos textos identificados para o processo de análise contribuiu para que pudessem ser elencadas três categorias emergentes, que caracterizaram os estudos acadêmicos no que se refere às possíveis abordagens para o ensino de Genética: 1. Estudos que tratam de aspectos históricos do ensino de Genética; 2. Estudos acerca dos conceitos de Genética trabalhados na Educação Básica; e 3. Estudos de aspectos da Genética Moderna.

Destacamos que as categorias se complementam, ou seja, identificamos trabalhos que expressam aspectos de duas categorias, como ocorre em P1, em que o autor buscou analisar livros didáticos de Biologia e a forma com que esses tratam o ensino da genética e seus temas embasadores. $O$ estudo realizado evidencia a preocupação com os conceitos trabalhados na Educação Básica e, ao analisar livros didáticos de Biologia, o autor aponta que, "é apresentada através de uma visão mais histórica e mais preocupada em mostrar a origem da genética, não discutindo, por exemplo, sua importância na evolução das ciências biológicas do século XX" (MANZKE, 1999, p. 88).

$\mathrm{Na}$ categoria que versa sobre os estudos que tratam de aspectos históricos do ensino de Genética, foram identificadas oito pesquisas. Nessas, observa-se o predomínio do tema relacionado à descoberta do DNA, como anuncia o excerto da P1 (1999, p. 40), "encaminhou-se uma nova área de conhecimento denominada engenharia genética. Através do conhecimento das técnicas de manejo do DNA, os cientistas passaram a identificar, a isolar e a multiplicar os genes dos mais diferentes seres vivos".

Para Scheid; Ferrari e Delizoicov (2005, p. 231), "a história do modelo de estrutura do DNA auxilia no entendimento dos conhecimentos atuais sobre o mecanismo de transmissão genética". Embora os alunos, na maioria das vezes, não consigam compreender a estrutura devido à sua complexidade, buscam-se novas estratégias para atender essa demanda curricular, uma vez que, conforme Santos (2020), o DNA está entre os cinco temas mais presentes nas provas do Exame Nacional do Ensino Médio - ENEM. 
As questões sobre a história da Ciência foram identificadas, também, em P4 (2004, p.201): "o planejamento e organização dos conteúdos de Genética podem ser feitos a partir de um diálogo estabelecido com a História da Genética, considerando como ocorreu seu desenvolvimento científico, as dificuldades para o estabelecimento das leis de Mendel e o estado do conhecimento da época" P4 (2004, p. 201), e em P31 (2017, p. 28): "a genética como área científica é lembrada em sua formação histórica normalmente pelas descobertas de Johann Mendel (1822-1884)".

De forma mais recorrente em nossa investigação, destacamos os estudos que tratam de conceitos de Genética trabalhados na Educação Básica, estes prevaleceram nos estudos acadêmicos considerados no presente trabalho, sendo identificadas em 29 pesquisas. $\mathrm{Na}$ análise das dissertações e teses, foi possível identificar os conceitos e o quão importantes são para a formação de alunos que concluem a Educação Básica.

A preocupação sinalizada nas pesquisas acadêmicas, indicadas nessa categoria, possibilita aferirmos que o foco dos estudos se concentra nos processos de ensino e de aprendizagem na Educação Básica brasileira. A análise de quais conceitos de Genética têm sido ensinados e, ainda, aspectos relacionados à aprendizagem dos alunos podem contribuir para um re-planejamento das estratégias de ensino utilizadas pelos professores e para o currículo escolar. Entre os conceitos de Genética apresentados nos estudos, observa-se em P1, “[...] temas embasadores da genética, os ácidos nucleicos, a teoria cromossômica, a divisão celular a gametogênese, por entender que esses assuntos são fundamentos teóricos de grande importância para o estudo desse capítulo da Biologia" [..] (1999, p. 8).

Nessa linha, em P2, o autor destaca que "a compreensão dos avanços em genética pressupõe o entendimento do conceito de gene, bem como do fluxo da informação genética. Este entendimento requer a superação da fragmentação do conhecimento em genética" (2001, p. 12). Ainda, identifica-se tal preocupação em P5, em que o autor afirma: "Coincidentemente, essa expressão, 'construção da dupla hélice', tem outro significado. A dupla hélice foi proposta através da construção de um modelo molecular concreto. No entanto, procuro lhe dar a dimensão social, mostrando alguns fatores sociais que conduziram sua construção. Desta forma, procurei contrapor a ciência que se faz àquela que, comumente, se transmite, se aceita e se concebe" (2005, p. 121).

Os excertos citados sinalizam que o ensino de Genética tem tido alterações ao longo dos anos, no que se refere aos conceitos abordados. De acordo com autores de P2 e P5, observamos a indicação dos avanços com relação aos conceitos e, de forma mais significativa, a relação com a dimensão social de tais conceitos.

Outros conceitos apresentados e discutidos nos trabalhos foram relacionados à divisão celular. Em P6 (2005, p. 120), o autor entende que o conteúdo de divisão celular (mitose e meiose) é fundamental, embora, "Em geral, os programas de ensino de biologia desvinculam os conteúdos sobre o núcleo e a divisão celular dos conteúdos de genética, criando um hiato pedagógico que dificulta a construção dos pré-requisitos necessários ao estudo da genética". Para P10 (2008, p.16) “[...] cabe, então, à Genética levar ao aprendiz a compreender como as 
informações genéticas definem a estrutura e a expressão gênica, funcionamento das células e determinam as características dos organismos, bem como a relação dessas com o ambiente".

Os conceitos de mitose e meiose têm sido trabalhados nas escolas de Educação Básica brasileira há muitos anos, pois são considerados conhecimentos básicos pela sua importância para a compreensão da Genética e pela sua conexão com diversos aspectos do cotidiano dos indivíduos (FRANZOLIN, 2012). No final do século XX, Manzke (1999) afirmou que a divisão celular se constitui em importante elo entre a gametogênese e a genética mendeliana e propôs a denominação desse tema e o estudo da gametogênese como "Temas Embasadores" ao estudo da genética.

Os aspectos da Genética Moderna, categorizados como a terceira classificação das pesquisas analisadas, relacionam-se a uma área de integração entre as novas tecnologias do DNA e novas aplicações em Genética, o que inclui a Biotecnologia e a Biologia Molecular. Desde a proposição da estrutura para a molécula do DNA, em 1953, os conhecimentos científicos tiveram avanços significativos e, como afirmam Silva e Kalhil (2017) esses avanços trouxeram um grande aporte de novas informações, antes restritas ao meio acadêmico e nos últimos anos, frequentemente, tratados pelos meios de comunicação de massa.

Para Xavier et. al. (2006, p. 277):

O destaque que estes temas apresentam pode ser explicado pelo grande apelo social e pela influência direta na vida das pessoas. São, portanto, conteúdos relevantes no contexto escolar. Debates frequentes, por exemplo, sobre transgênicos, terapias gênicas, clonagem, células-tronco, teste de paternidade etc. vêm sendo travados e a sala de aula não pode ficar alheia às novidades ou deixar de abraçar a Nova Biologia.

Nessa direção, temos o excerto do estudo P22 (2015, p. 20) que afirma: "Na perspectiva de fomentar novas maneiras de ensinar Biologia, surge a possibilidade de abordar temas atuais que motivem e envolvam os estudantes no processo de construção de conceitos sobre biotecnologia, mutação e transgênicos por considerá-los importantes no cotidiano". Igualmente, P27 (2016, p. 13) "Consideramos que uma análise sobre os discursos de Genética Moderna se torna interessante pois trata-se de temas que estão sendo amplamente debatidos na sociedade nos últimos anos, estando em pauta em vários setores (como as mídias, a política, em discussões econômicas, éticas, morais, etc.) sociais" e P28 $(2017$, p. 63) "a elaboração de ensino partiu da problematização de temas relacionados a genética e a biotecnologia".

A Genética Moderna traz à tona reflexões sobre as finalidades da educação científica, como se pode perceber nos excertos P38 (2019, p. 11) “O desenvolvimento da Genética e da Biologia Molecular, das tecnologias de manipulação do DNA e de clonagem traz à tona aspectos éticos envolvidos na produção e aplicação do conhecimento científico e tecnológico, chamando à reflexão sobre as relações entre a ciência, a tecnologia e a sociedade" e P8 (2006, p. 39) “A educação em genética humana deve promover nos alunos o desenvolvimento das habilidades de tomar decisões, reconhecer alternativas, aplicar informações e selecionar opções relativas à saúde em nível comunitário e pessoal; os estudantes devem ser preparados para utilizar os conceitos da área para entender e opinar em relação a aspectos sociais e éticos desse campo de conhecimento". Essas considerações são corroboradas por Silva e Kalhil (2017, p. 126-127) ao 
entenderem que "a Genética é aquela disciplina que pode interferir diretamente na forma de participação na sociedade, colaborando na formação de um sujeito social mais crítico, autônomo e comprometido com sua cidadania".

Estudos que tratam da Genética Moderna têm sido propostos em documentos curriculares no Brasil. Desde a sua publicação, os PCNEM vêm procurando sugerir reformas educacionais (BRASIL, 2000), inserindo visões atualizadas da Biologia, nomeadamente no que se refere à Genética.

Segundo esses documentos, dois dos seis novos temas que estruturam a disciplina de Biologia relacionam-se ao estudo e à aplicabilidade de novas tecnologias associadas ao DNA, tais como: a transferência do DNA de um organismo para outro (enzimas de restrição, vetores e clonagem molecular), a participação da engenharia genética na produção de alimentos, herbicidas, produtos farmacêuticos, hormônios, de vacinas e de medicamentos; as técnicas moleculares utilizadas para a detecção precoce de doenças genéticas; a importância dos testes de DNA para determinação da paternidade, investigação criminal ou identificação de indivíduos e a compreensão da natureza dos projetos genomas, especialmente dentro do país (XAVIER et. al., 2006, p. 277).

Mais recentemente, a BNCC (BRASIL, 2018) propõe, na área de Ciências da Natureza e suas Tecnologias, as seguintes competências específicas com suas respectivas habilidades: a genética mendeliana, aplicação da tecnologia do DNA recombinante; identificação por DNA; emprego de células-tronco, herança biológica; darwinismo social, entre outros, para que seus conhecimentos conceituais possam ser mobilizados, permitindo aos estudantes entenderem a vida em sua diversidade de formas e níveis de organização e atribuindo importância à natureza e seus recursos, reconhecendo a imprevisibilidade de fenômenos, bem como os limites das explicações e do próprio conhecimento científico. A compreensão desses processos é essencial para um debate fundamentado sobre os impactos da tecnologia nas relações humanas, sejam elas locais ou globais, e suas implicações éticas, morais, culturais, sociais, políticas e econômicas, e sobre seus riscos e benefícios para o desenvolvimento sustentável e a preservação da vida no planeta.

\section{Considerações Finais}

No presente estudo, realizado a partir de uma revisão bibliográfica de literatura sobre Ensino de Genética no Brasil foram encontradas 39 pesquisas, sendo essas: nove teses e 30 dissertações. A revisão foi realizada por meio do levantamento dos principais trabalhos publicados no período de 1999 a 2019, na BDTD, localizada no IBCIT, tendo como descritor "Ensino de Genética".

O período de 20 anos, abrangido pela pesquisa, foi de suma importância, pois tornou possível observar a trajetória que o ensino de Genética perpassou e o quanto cada fase curricular da história da educação esteve presente. Nessa trajetória histórica, verificou-se a influência que o sistema educacional brasileiro exerce sobre a pesquisa, devido às propostas curriculares que the servem de norteadoras. 
Os resultados apontam que, em relação à periodicidade dos estudos, nos primeiros dez anos (1999-2009), desenvolveram-se doze pesquisas relacionadas à temática. Nos dez anos subsequentes (2010-2019), o número de trabalhos que tratavam do ensino de Genética aumentou consideravelmente, sendo encontradas 27 pesquisas. As regiões brasileiras nas quais se concentraram as publicações sobre Ensino de Genética, foram a Região Sul, com o Estado de Santa Catarina em destaque, seguida pela Região Sudeste.

Os estudos acerca dos conceitos de Genética abordados na Educação Básica prevaleceram e se referem majoritariamente ao Ensino Médio. Dentre esses conceitos, o conceito de DNA foi apontado como uma das principais dificuldades de aprendizagem dos alunos. Também foram empregadas diferentes estratégias de pesquisa, destacando-se a análise de recursos didáticos.

Diante desses resultados, pode-se inferir que a expressiva publicação de temas relacionados ao ensino de Genética pode ser um bom indicativo de como as áreas de pesquisa em Educação e em Ensino tem priorizado essa temática, em detrimento de outros temas sobre conteúdo/conceitos mais específicos. Isso pode indicar que há uma saudável preocupação com as questões referentes ao currículo, às metodologias e concepções de ensino.

Além disso, na recolha de dados e na análise das pesquisas no formato de teses e dissertações, percebe-se que elas reforçam o alerta sobre a dificuldade de aprendizagem de conceitos básicos do ensino de Genética. Essa constatação pode indicar que é preciso investigar, com mais profundidade, as causas dessa alegada dificuldade.

Por outro lado, nas pesquisas que apresentam a grande dificuldade dos alunos se apropriarem de conceitos básicos de Genética, constata-se que o professor, ao oportunizar formas diferenciadas de ensino, tais como: jogos didáticos, modelos didáticos, sequência didática e outras formas de propostas metodológicas, diminuiu a dificuldade descrita, obtendo resultados positivos de aprendizagem.

Em relação aos aspectos relevantes analisados nas pesquisas sobre os livros didáticos, os resultados encontrados indicam que há uma descontextualização deles em relação a realidade dos alunos. Em vista disso, entendemos que os órgãos públicos que implementam a política pública do livro didático deveriam considerar esses resultados apurados em pesquisas, ao ofertar os livros que servem de apoio didático ao processo de ensino e aprendizagem nas escolas do País. Entretanto, cabe salientar que "é preciso levar em conta que o livro didático não é e não deve ser o único recurso pedagógico utilizado pelos professores para o desenvolvimento de práticas pedagógicas", como advertem Radetzke, Leite e Wenzel (2019, p. 133).

Contudo, todas essas percepções oriundas de pesquisas, precisam chegar até os professores da Educação Básica. Para isso, a recomendação é de que esses resultados sejam divulgados aos docentes nos momentos de formação continuada.

\section{Referências}


BANDEIRA, D. Materiais didáticos. Curitiba, PR: IESDE, 2009. 456 p. Disponível em: http://arquivostp.s3.amazonaws.com/qcursos/livro/LIVRO materiais didaticos.pdf. Acesso em: 16 jun. 2020.

BARDIN, L. Análise de conteúdo. São Paulo: Edições 70, 2011.

BRASIL. SECRETARIA DE EDUCAÇÃO FUNDAMENTAL. Parâmetros Curriculares Nacionais Ensino Médio (PCNEM). Brasília: MEC/SEF, 2000. Disponível em: http://portal.mec.gov.br/seb/arquivos/pdf/blegais.pdf. Acesso em: 11 dez. 2020.

BRASIL. Ministério da Educação. Base Nacional Comum Curricular (BNCC). Educação é a base. 2018. Disponível em: http://basenacionalcomum.mec.gov.br/. Acesso em: 16 jun. 2020.

BRASIL. Ministério da Educação. Ciências da natureza, matemática e suas tecnologias. Secretaria de Educação Básica. Volume 2. Brasília: Secretaria de Educação Básica, 2006. Disponível em: http://portal.mec.gov.br/seb/arquivos/pdf/book volume 02 internet.pdf. Acesso em: 15 jun. 2020.

DELLA JUSTINA, L. A.; FERLA, M. R. A utilização de modelos didáticos no ensino de genética exemplo de representação de compactação do DNA eucarioto. Arquivos do mudi, 10 (2), 35-40, 2006.

FRANZOLIN, F. Conhecimentos básicos de Genética segundo professores e docentes e sua apresentação em livros didáticos e na academia: aproximações e distanciamentos. (Tese de doutorado). Universidade de São Paulo, SP. 2012. 674 f. Disponível em: https://www.teses.usp.br/teses/disponiveis/48/48134/tde-23082012-093226/pt-br.php.

Acesso em: 26 jun. 2020.

FERREIRA, P.F.M.; JUSTI, R.S. A abordagem do DNA nos livros de biologia e química do ensino médio: Uma análise crítica. 2004. Disponível em: https://www.scielo.br/pdf/epec/v6n1/19832117-epec-6-01-00038.pdf. Acesso em: 12 de abril de 2021.

GÜLLICH, R. I. C. Investigação-formação ação em ciências: um caminho para reconstruir a relação entre livro didático, professor e o ensino. Curitiba: Prismas, 2013.

JUSTINA, L. A. D. Ensino de genética e história de conceitos relativos à hereditariedade. 2001. Dissertação (Mestrado em Educação) - Universidade Federal de Santa Catarina, Florianópolis, 2001.

LÜDKE, M.; ANDRÉ, M.E.D.A. Pesquisa em educação: Abordagens Qualitativas - [2. ed]. [Reimpr.]. - Rio de Janeiro: E.P.U., 2018.

MANZKE, V. H. B. Aspectos da interação entre o professor de biologia e o livro didático no ensino de genética na cidade de Pelotas, RS. Dissertação (Mestrado) - Universidade Federal de Santa Catarina, Centro de Ciências da Educação. Florianópolis, 1999. Disponível em: http://repositorio.ufsc.br/xmlui/handle/123456789/81257. Acesso em: out. 2020.

MOROSINI, M. C.; Fernandes, C. M.B. Estado do Conhecimento: conceitos, finalidades e interlocuções. 2014.

Disponível

em: 
https://revistaseletronicas.pucrs.br/ojs/index.php/porescrito/article/view/18875/12399.

Acesso em: abril 2021.

OCA, I. C. M. ¿Qué aportes ofrece la investigación reciente sobre aprendizaje para fundamentar nuevas estrategias didácticas? Revista Educación, México, v. 19, n. 1, 2010, p. 7-16.

RADETZKE, F. S.; LEITE, F. A.; WENZEL, J. S. Relações Conceituais em Ciências da Natureza: um olhar para os livros didáticos. Ensino de Ciências e Tecnologia em Revista, Vol. 9, n. 3. Set./Dez. 2019.

ROMANOWSKI, J. P.; ENS, R. T. As pesquisas denominadas do tipo "Estado da Arte". Diálogos Educacionais, v. 6, n. 6, p. 37-50, 2006.

SANTOS, V. S. Os 5 temas de Biologia mais cobrados no Enem. Brasil Escola, 2020. Disponível em: https://brasilescola.uol.com.br/biologia/os-5-temas-biologia-mais-cobrados-no-enem.htm Acesso em: 15 jun. 2020.

SCHEID, N. M. J.; FERRARI, N. A história da ciência como aliada no ensino de genética. Genética na Escola, v. 1, n. 1, p. 17-18, Ribeirão Preto, 2006.

SCHEID, N.M.J. Os conceitos de genética e as implicações na docência. Dissertação (Mestrado em Educação na Ciência) Departamento de Pedagogia, UNIJUI, Ijuí, 2001.

SCHEID, N. M. J.; FERRARI, N.; DELIZOICOV, D. A construção coletiva do conhecimento científico sobre a estrutura do DNA. Ciência \& Educação, Bauru, v. 11, n. 2, p. 231, 2005.

SILVA, C. C. da; KALHIL, J. B. A aprendizagem de genética à luz da Teoria Fundamentada: um ensaio preliminar. Ciênc. educ. (Bauru), Bauru, v. 23, n. 1, p. 125-140, Mar. 2017. Disponível em: $\quad<h t t p: / / w w w . s c i e l o . b r / s c i e l o . p h p ? s c r i p t=s c i \_a r t t e x t \& p i d=S 1516$ 73132017000100125\&lng=en\&nrm=iso>. Acesso em: $11 \mathrm{dez} .2020$.

XAVIER, M. C. F.; FREIRE, A. S.; MORAES, M. O. A nova (moderna) biologia e a genética nos livros didáticos de biologia no ensino médio. Ciênc. educ. (Bauru), Bauru, v. 12, n. 3, p. 275-289, Dec. 2006. Disponível em: <http://www.scielo.br/scielo.php?script=sci_arttext\&pid=S1516$73132006000300003 \&$ Ing=en\&nrm=iso $>$. Acesso em: $11 \mathrm{dez} .2020$.

ZABALA, A. A prática educativa: como ensinar. Porto Alegre: Artmed, 1998. 